\title{
O café nosso de cada dia: investigação da influência de uma situação de estudo no processo de ensino aprendizagem de ciências da natureza no ensino médio
}

Danilo de Jesus danilo.quimica@hotmail.com 0000-0001-8769-1067

Instituto Federal de Educação, Ciência e Tecnologia da Bahia Valença, Bahia.

Neurivaldo José de Guzzi Filho neurivaldo@gmail.com 0000-0001-7366-3858 Universidade Estadual de Santa Cruz

\begin{abstract}
RESUMO
O café é uma das bebidas mais consumidas no mundo, por este fator, pode ser forte instrumento para ensino de Ciências de forma contextualizada, visto que o ensino tradicional não tem obtido grandes resultados com os estudantes da atualidade promovendo a falta de atenção e desestimulando os alunos que, na maioria dos casos, não conseguem perceber a relação entre os conteúdos estudados em sala de aula e sua vivência social. Diante disso, a Situação de Estudo (SE) aparece como uma importante promessa de evolução no campo de reformulação curricular, onde os conteúdos são trabalhados de forma coletiva e integrada. Nesse texto apresentamos relatos de uma pesquisa de mestrado, cujo objetivo foi investigar a eficiência de uma Situação de Estudo como proposta curricular para alguns assuntos de Química, Física, Biologia e História de forma contextualizada e interdisciplinar, baseando-se no tema café.
\end{abstract}

PALAVRAS-CHAVE: Ensino de ciências. Situação de estudo. Café. 


\section{INTRODUÇÃO}

Jesus caminhava em passos lentos, arrastados, cansados, carregando uma cruz de madeira pesada num de seus ombros. Com sede, pedia água e ninguém o atendia. Em seu caminho haviam alguns arbustos que não floresciam nem frutificavam e, por isso, eram considerados inúteis. Suas folhas verde-escuras, arredondadas, meio convexas, guardavam o orvalho que caíra no sereno da última noite. Ao passar por entre esses arbustos, o rosto de Jesus tocou em suas folhas e orvalho caiu sobre sua face ensanguentada fazendo diminuir, ainda que suavemente, o tormento da dor causada pela sede. Uma das folhas retornou ao seu lugar marcada por três gotas redondas e brilhantes do sangue do Nazareno. Este, ainda que muito cansado, sorriu e resolveu retribuir o benefício que o tão triste arbusto lhe causou, transformando as gotas de sangue em frutos vermelhos que fariam da árvore uma das espécies mais cultivadas no mundo inteiro. Deste modo nascia lendariamente o primeiro arbusto de café (GALETI, 2004).

Hoje em dia o café é uma das bebidas mais consumidas do mundo, por este fator, pode ser forte instrumento para ensino de Ciências, visto que autores como Santos e Schnetzler (1996) acreditam que a seleção dos assuntos tem um relevante papel para que se mude o cenário da educação atual. Sabe-se que, atualmente a educação tradicional não tem obtido grandes resultados com os estudantes, promovendo a falta de atenção e desestimulando os alunos que, na maioria dos casos, não conseguem perceber a relação entre os conteúdos estudados em sala de aula e sua vivência social. Boa parte desse cenário deve-se à metodologia adotada nas escolas, que foi criada num momento histórico em que se buscava a formação de mão de obra profissional e técnica. $\mathrm{O}$ aluno precisava dominar alguns conhecimentos científicos considerados importantes para o momento.

O tempo passou mas as práticas educacionais ainda continuam parecidas em muitas das escolas em nosso país. Moraes e Mancuso (2004) afirmam que na maior parte das instituições, as Ciências Naturais têm sido ensinadas de maneira pouco produtiva e desinteressante devido à forma fragmentada e linear em que estão divididas, sem levar em consideração o contexto em que os alunos estão inseridos, sem abrir possibilidades para exploração de outros aspectos, aumentando o desgaste do aluno no processo de ensino.

Maldaner (2007) relata que o Ensino Médio é visto como um trampolim para o ensino superior e muitas vezes encarado como uma preparação para os vestibulares, que têm sido substituídos pelo ENEM na atualidade. O que não está de acordo com os Parâmetros Curriculares Nacionais para o Ensino Médio (BRASIL, 1999), que recomenda uma prática de ensino das Ciências de modo a possibilitar um conhecimento científico voltado para a formação de valores educativos, éticos e humanísticos que permitam ao aluno ir além da aprendizagem de fatos, leis e teorias. $\mathrm{O}$ ensino deve estar voltado para a formação do aluno/cidadão para que atue na sociedade da qual faz parte, onde as Ciências aparecem como relevantes no cotidiano de todas as pessoas.

O papel central da escola é o de instrumentalizar o estudante para entender situações, coisas e fatos presentes no seu cotidiano possibilitando novas interações, interpretações e compreensões da sua realidade à luz do conhecimento científico construído ao longo do tempo. Para atingir tal objetivo, o 
construção e apropriação do conhecimento por parte dos alunos. Para auxiliar o professor na execução desta sua extraordinária função, cabe destacar a

elaboração de propostas de organização curricular, originadas da observação e da pesquisa sobre os sistemas de ensino e aprendizagem ocorrentes tanto nas licenciaturas, quanto na Educação Básica, com propósitos de propiciar o diálogo entre a vivência dos estudantes e as explicações das Ciências como um saber estruturado (BOFF; PANSERA-DE-ARAÚJO, 2012, p. 125).

Concordando com as autoras, na tentativa de responder às questões apontadas e ultrapassar a visão de ensino tradicional, acata-se a elaboração da proposta de organização curricular denominada Situação de Estudo (SE).

A Situação de Estudo é uma proposta de inovação curricular que pretende romper com a linearidade e a fragmentação do currículo escolar atual. Neste aspecto, pretende promover o ensino baseado no desenvolvimento de sucessivas Situações de Estudo ao longo do ensino médio, abordando os assuntos que forem pertinentes a cada tema, desfazendo a relação habitual de um conteúdo ligado a uma série específica. Nessa proposta, várias estratégias de ensino podem ser articuladas com o objetivo de promover a melhoria do ensino, para isso, a participação de professores, alunos de graduação e profissionais da administração escolar devem interagir na construção das SEs (MALDANER et al., 2007).

Neste artigo apresentamos um trabalho desenvolvido como dissertação de mestrado, cujo objetivo geral foi investigar a eficiência de uma Situação de Estudo como proposta curricular para alguns assuntos de Química, Física, Biologia e História de forma contextualizada e interdisciplinar, baseando-se no tema café. Para isso, buscamos analisar os limites e possibilidades do tema café na elaboração e desenvolvimento de uma Situação de Estudo, combinada com experimentação de caráter problematizador, utilizando as características de protagonismo e cooperativismo do método Jigsaw ${ }^{1}$, bem como também procuramos verificar se a produção de vídeo pode ser um bom instrumento para avaliação de conteúdos desenvolvidos por meio de uma Situação de Estudo.

\section{A Situação de Estudo}

Muito se fala na necessidade de melhorias na educação em nosso país e muitas são as críticas ao ensino realizado nas instituições de ensino, que segundo Chassot (1995) não é capaz de produzir significado aos estudantes. A necessidade de inovações no ensino de ciências, praticado na maioria das escolas, é defendida por autores e pesquisadores, além de sugerida pelos documentos oficiais do Ministério da Educação. Entre as várias tentativas de melhoria do ensino praticado no país, destaco a Situação de Estudo sugerida por um grupo de pesquisadores do ensino de Ciências no Rio Grande do Sul denominado Grupo Interdepartamental de Pesquisa sobre Educação em Ciências da Universidade Regional do Noroeste do Estado do Rio Grande do Sul (GIPEC-UNIJUÍ) no ano 2000. Entretanto o grupo de

\footnotetext{
${ }^{1} \mathrm{O}$ método Jigsaw é uma estratégia de ensino baseada na cooperação entre os indivíduos. Consiste em formar, inicialmente, grupos de base e dividir o assunto em tantos subtemas quantos forem os membros do grupo, cada componente responsabiliza-se por um subtema. Em seguida, são formados outros grupos com os membros responsáveis por um mesmo subtema, formando assim grupos de especialistas num determinado tema que devem aprimorar seu aprendizado no assunto que lhe foi incumbido. A terceira etapa consiste em retornar os alunos Página 1110 orupo base e socializar o conhecimento obtido em cada grupo de especialistas (FATARELI et al., 2010).
} 
pesquisadores já desenvolve parcerias em trabalhos na área há cerca de 28 anos. O grupo foi influenciado pela preocupação com a educação científica que se intensificou nas três últimas décadas em nível internacional. Com isso, tende a produzir material didático para o ensino de Ciências, propostas de mudanças curriculares e formação de professores com base em temas de grande conhecimento da comunidade em geral (MALDANER et al., 2007)

Com forte influência das características históricas do grupo GIPEC-UNIJUÍ, que trabalhava a formação inicial e continuada de professores e a produção de material didático, o foco dirigiu-se para a produção coletiva da proposta curricular denominada Situação de Estudo, cujo significado almejado e elaborado inclui

\footnotetext{
contextualização, inter e transdiciplinaridade, abordagens metodológicas diversificadas, orientações curriculares oficiais, conhecimentos prévios de estudantes e professores, tecnologia e sociedade, tradição escolar e acadêmica, múltiplas fontes de informação e, principalmente, compromisso com o estudo (MALDANER et al., 2007).
}

Os idealizadores da proposta acreditam que é necessário romper com as visões lineares e fragmentadas do ensino disciplinar em ciências e afirmam que a SE proporciona isso à medida que propõe a articulação de saberes e conteúdos científicos das diversas áreas entre si, e também os articula com os saberes e conhecimentos cotidianos que os alunos produziram e internalizaram em suas diversas vivências em espaços diferentes da escola. Dessa maneira, a abordagem nesses moldes seria feita com características "interdisciplinares, intercomplementares e transdisciplinares” (MALDANER; ZANON, 2006).

Maldaner e Zanon (2006) apresentam a Situação de Estudo como uma importante promessa de evolução no campo de reformulação curricular, onde os conteúdos são trabalhados de forma coletiva e integrada. Segundo Maldaner (2007), Situação de Estudo é uma circunstância corriqueira aos alunos, vivenciada constantemente por muitas pessoas e, por consequência, de conhecimento comum. Assim, numa SE o assunto estudado é de amplo conhecimento de todos e ocorrerá o estudo científico dessa situação, que deve englobar diversos conceitos de múltiplos campos científicos para permitir uma interação entre as diversas áreas do conhecimento. Isso pode ser constatado no trecho transcrito a seguir: "Situação de Estudo é uma situação concreta, da vivência dos alunos, rica conceitualmente para diversos campos da ciência, de forma a permitir a análise interdisciplinar e estabelecer interconexões transdisciplinares" (MALDANER, 2007, p. 248).

Freire (1987) afirma ser necessário a inserção de temas sociais na composição do currículo escolar. Para ele, faz-se necessário que estes temas representem contradições sociais vivenciadas por toda a comunidade escolar, pois assim o ensino praticado na escola terá uma relação íntima com a vivência da população e, portanto, adquire significado para os alunos e os demais envolvidos no processo de ensino.

Edgar Morin (2000) também chama atenção para a necessidade de contextualização do ensino praticado nas escolas, além disso, ele apresenta a necessidade de interligação entre as disciplinas, para proporcionar um conhecimento capaz de suscitar uma conexão entre as partes e promover domínio e entendimento do conjunto sob os diversos olhares das disciplinas ou campos do saber. 
Quando se fala em currículo deve-se levar em consideração a incompatibilidade entre os objetivos da escola e as pretensões dos alunos. Os alunos da atualidade não reagem ao ensino tradicional como os alunos de três ou quatro décadas atrás e o que é pretendido pela escola não é o mesmo que é desejado pelos estudantes. A escola deve ensinar o aluno a pensar, ensiná-lo a tomar posse do conhecimento e usá-lo do jeito que lhe for mais conveniente ao longo de sua vida, tendo consciência dos atos e as consequências destes (BOFF; PANSERA-DE-ARAÚJO, 2011). Nesse sentido a formação inicial do professor tem importância fundamental em prepará-lo para reagir autonomamente na resolução de situações-problema como esta.

Talvez a utilização de situações cotidianas nas aulas seja uma saída para prender a atenção dos alunos. Quando o professor apresenta problemas da vida real aos estudantes, solicitando ou sugerindo soluções para eles, proporciona uma espécie de desafio a ser resolvido, o que pode ser uma saída para conectar os anseios do professor com o interesse dos alunos. A SE é uma forma real e efetiva de proporcionar a construção da significação dos conceitos e do conhecimento científico, através da exploração, na escola, de um tema da vivência dos alunos e, consequentemente, de conhecimento de todos. Autores como Santos e Schnetzler (1996) acreditam que a seleção dos assuntos de Química tem um papel relevante para que se mude o cenário da educação atual, como se pode observar no trecho:

\footnotetext{
Os temas químicos sociais desempenham papel fundamental no ensino de Química para formar o cidadão, pois propiciam a contextualização do conteúdo químico com o cotidiano do aluno. Além disso, os temas químicos permitem o desenvolvimento das habilidades básicas relativas à cidadania, como a participação e a capacidade de tomada de decisão, pois trazem para a sala de aula discussões de aspectos sociais relevantes, que exigem dos alunos posicionamento crítico quanto a sua solução (SANTOS; SCHNETZLER, 1996, p. 30)
}

Dessa forma, o ensino das Ciências deve estar baseado em temas relacionados ao cotidiano dos alunos visando esclarecer situações reais. Acredita-se que assim teremos um ensino mais estimulante e menos cansativo capaz de proporcionar maior curiosidade aos educandos, papel muito bem desempenhado pelas Situações de Estudo, tornando o estudo prazeroso, formando cidadãos conscientes e esclarecidos a respeito dos temas sociais da atualidade. Estes cidadãos deverão ser capazes de interferir de maneira consciente na sociedade em que estão inseridos, modificando-a no sentido de torná-la o mais próximo possível do desejado.

Nesse papel de formar cidadãos, a escola desempenha uma função de grande importância. Entretanto, o que tem sido praticado está longe das necessidades para atingir tal objetivo. Boa parcela de culpa está nos currículos estabelecidos para serem seguidos.

Maldaner et al. (2007) relembram um momento histórico em que os currículos escolares foram produzidos por especialistas de cada área de ensino e transferidos às escolas, para que os professores apenas os utilizassem como normas a serem seguidas enquanto ensinavam seus alunos, sem levar em consideração os diferentes contextos que existem no Brasil, cujas diferenças geográficas, sociais e culturais são muito grandes. 
Os mesmos autores afirmam que a participação de professores das escolas na produção de currículos começou a ganhar destaque a partir da metade da década de 80 do século passado, quando a publicação de livros com orientações curriculares de propostas conhecidas como alternativas ao ensino de Ciências, começou a mostrar o sucesso de parcerias na produção curricular envolvendo docentes de escolas em conjunto com professores e alunos das licenciaturas.

Isso levou os pesquisadores que criaram a SE a acreditarem que o processo de planejamento, elaboração e desenvolvimento de uma Situação de Estudo, tanto no Ensino Fundamental quanto no Ensino Médio, deve envolver profissionais de diferentes níveis e diferentes formações interagindo entre si, a exemplo de professores de universidades, professores de escolas, alunos de graduação, pesquisadores do ensino, entre outros profissionais da educação que, preferencialmente, devem ter formação inicial em diferentes áreas.

Uma Situação de Estudo não pode ser uma produção de terceiros, para ser aplicada numa escola diferente do contexto em que foi produzida. Ela deve ser pensada e construída por um conjunto de pessoas que adotem e assumam a responsabilidade pela sua criação e desenvolvimento. Não pode ser uma produção completamente produzida fora da escola, para os professores apenas repetirem o que alguém criou, ela precisa ter as características do pessoal onde será desenvolvida. Esse coletivo pode ser um conjunto de professores de uma disciplina, uma área, mas é preferível que haja profissionais de áreas distintas interagindo na criação e desenvolvimento da SE escolhida (SANGIOGO et al., 2013).

Dessa forma, pode-se produzir SEs com as características desejáveis que, segundo Maldaner (2007) consiste em:

\footnotetext{
[...] contemplar um número relativamente pequeno de conceitos centrais sendo estes sempre representativos da disciplina, compondo uma totalidade para cada disciplina e para o conjunto delas; preocupar-se em transacionar apenas significados iniciais para conceitos que aparecem pela primeira vez, podendo evoluir no desenvolvimento das SEs; estimular a produção criativa e coletiva dos estudantes sobre o entendimento da situação estudada como uma totalidade, utilizando o máximo de instrumentos culturais de divulgação, como textos, exposições orais, imagens, internet, tabelas, gráficos, encenações e outros; permitir que sejam significados os conhecimentos científicos contemporâneos, uma decorrência natural quando se estuda uma situação concreta e as soluções tecnológicas atuais (MALDANER, 2007, p. 249-250).
}

O desenvolvimento de uma SE deve ter duração aproximada de dois a três meses de aula, que devem ser planejados de acordo com o regimento e calendário da instituição de ensino. Dessa maneira, busca-se evitar a exaustão do assunto e consequente cansaço nos alunos. Isso sugere uma projeção de 9 a 12 SEs sucessivas para abordagem dos assuntos planejados para todo o ensino médio, a duração específica fica a critério da instituição e depende da maneira como está organizada esta modalidade de ensino na instituição (MALDANER et al., 2007).

É importante que no decorrer das atividades, as disciplinas se alternem no papel de protagonista em cada Situação de Estudo. Assim, ao final do desenvolvimento de uma SE cuja principal disciplina foi Química, a seguinte deve ser outra, como Física ou Biologia por exemplo. Deve acontecer um revezamento na função de "carro chefe" da Situação de Estudo. As demais devem agir como auxiliares, emprestando seus saberes, ensinamentos, técnicas e princípios para 
proporcionar o entendimento global do tema. Aconselha-se que as disciplinas se alternem nesta função, para que cada uma possa assumir o papel de protagonista do processo. Os professores trabalham em conjunto, com uma importante abertura para a participação de todas as disciplinas envolvidas (MALDANER et al., 2007).

No desenvolvimento de uma SE cada professor trabalha os conceitos referentes à sua disciplina, abordando os aspectos característicos de cada área. Nesse sentido, faz-se importante demonstrar as características de cada uma, mostrando as similaridades e diferenças entre cada área do saber. Também é importante a inserção de palavras representativas de conceitos, características de cada disciplina, os atores do processo de ensino devem utilizar constantemente esta palavra para que seja construído um significado para ela na conjuntura específica que está em estudo. Este significado ganha a forma do contexto em que está sendo utilizado e poderá evoluir para outros campos do saber, uma vez que a Situação de Estudo é desenvolvida num meio interdisciplinar. Dessa forma, a palavra representativa passa a constituir a mente do aluno e possibilitará a utilização do conceito em outra situação que se faça necessário (SANGIOGO et al., 2013).

A Situação de Estudo é uma proposta de ensino que considera o professor como instrumento mediador do conhecimento, buscando formas alternativas de ultrapassar o "estrangulamento" do atual currículo de Ciências. Essa proposta considera a vivência social dos estudantes, requisitando que eles tragam fatos e conhecimentos do cotidiano para a sala de aula expondo-os em suas falas, mediadas pelo professor, fazendo com que o objeto de estudo não seja explicado apenas pela exposição docente, mas sim, entendido pelo conjunto das experiências de todos os sujeitos envolvidos no processo (SILVA et al., 2007).

Esse formato de aprendizagem busca entender um objeto de estudo partindo do conhecimento dos estudantes, não define uma sequência linear de assuntos a serem abordados. Eles são utilizados à medida que são necessários para a compreensão do que se está analisando. Assim, são convocados saberes das diversas áreas à medida que surge necessidade deles, facilitando a interação entre professores e disciplinas distintos numa forma interdisciplinar de produção de conhecimentos e, consequentemente, se promove uma aprendizagem dotada de significados articulada nos diferentes contextos dos conceitos científicos (SILVA et al., 2007).

Em torno da situação escolhida, organizam-se conteúdos das diversas Ciências que vão servir de instrumentos para o entendimento de uma determinada vivência prática do mundo material. Não é preciso destacar e apontar os conteúdos usados em cada disciplina, pois isso os professores devem conhecer e já os conhecem. Eles aparecem de acordo com a necessidade de cada um para a análise, entendimento e compreensão do objeto de estudo. Desse modo supera-se a visão da multidisciplinaridade e atinge-se o nível da inter e transdiciplinaridade através da complementaridade dos conceitos utilizados (MALDANER et al., 2007).

Esse objeto de estudo referido anteriormente é um tema sobre o qual se pretende produzir entendimento. Ele deve ser de amplo conhecimento de todos, sobre o qual os envolvidos no processo educacional devem ter algo a falar, além de ser conceitualmente rico, ele precisa permitir abordagens das diversas áreas (MALDANER, 2004). À medida que os conhecimentos dos estudantes são levados 
à sala de aula através da fala dos alunos, cabe ao professor aproveitar essas interações, problematizando-as e questionando-as no sentido de aumentar os significados dos estudantes sobre o assunto em questão. As ideias iniciais deles precisam ser valorizadas e consideradas, para então permitir a continuidade do processo de significação e assim, permitir possibilidades de compreensões cada vez mais complexas da ideia inicial que foi exposta, fortalecendo dessa maneira, a ideia de que eles são parte importante do processo de ensino aprendizagem (FRISON et al., 2007)

A concepção e organização curriculares em que se baseia teoricamente a Situação de Estudo, busca privilegiar interações na relação pedagógica entre os sujeitos. É por meio das interações que o ser humano se desenvolve e constitui seus significados para todas as coisas da vida, criando consciência de seu tempo com relação ao passado e também ao futuro. Conforme Vigotski, o processo de aprendizagem ocorre pela interação com o outro, mediado pela linguagem. É dessa forma que acontecem todas as aprendizagens da nossa espécie, tanto as cotidianas, informais e não-formais, como também aquelas intencionais da escola formal. A linguagem exerce papel muito mais importante que simples meio de comunicação: ela exerce papel fundamental junto à constituição dos pensamentos. As palavras ou sinais são importantes para que aconteça o desenvolvimento dos pensamentos. É na interação com o outro que as palavras e símbolos são significados, permitindo a evolução para níveis mais complexos de entendimento. Dessa forma o pensamento pode evoluir e atingir níveis cada vez mais elevados, capaz de permitir entendimento de abstrações cada vez mais severas, aproximando-se do pensamento científico (MALDANER; ZANON, 2006).

Para assegurar o diálogo entre uma situação real e concreta, trazida da vivência dos alunos, com o saber disciplinar das Ciências, é essencial que os professores saibam aproveitar corretamente as manifestações dos estudantes para problematizá-las a fim de construir um conhecimento científico a partir do que eles já trazem consigo, valorizando esse conhecimento inicial e a fala dos educandos (FRISON et al., 2007). Isso por si só já promove a contextualização e a interação de conhecimentos de diferentes disciplinas promovendo assim uma maneira interdisciplinar de educação e, dependendo do assunto, outros níveis de entendimento como pluri, multi e transdisciplinares também podem ser atingidos pelos professores e estudantes (MALDANER, 2004).

Ao final deve ser feito um fechamento com uma atividade que proporcione uma avaliação global do conhecimento que foi produzido, "isso engloba uma avaliação interdisciplinar e transdisciplinar sobre o uso de conceitos significados na análise de uma situação concreta que tenha relação com o estudo realizado" (MALDANER et al., 2007, p. 128). Dessa maneira, não está se rompendo apenas com a maneira tradicional de organizar o currículo, mas também com as formas de avaliação baseadas na memorização de conteúdos.

\section{A pesquisa}

A atual situação do nosso sistema educacional exige novas formas em pensar e produzir conhecimento e por isso, necessitamos de pesquisas que abarquem essas necessidades, que sejam capazes de produzir respostas às questões educacionais e, deste modo, auxiliar nas escolhas de alternativas viáveis à melhoria 
da educação em nosso país. Nesse sentido, a pesquisa social aparece como uma importante aliada na produção desse conhecimento, uma vez que, este tipo de pesquisa visa investigar as relações sociais estabelecidas por seres humanos, enquanto seres pensantes que possuem uma historicidade com crenças e valores próprios. Considerando tais fatores, a modalidade de pesquisa escolhida para este trabalho foi a qualitativa, concordando com as autoras Ludke e André (1986), que apontam as características desta modalidade de pesquisa que possibilitam a análise das complexas relações entre a escola e a sociedade.

A pesquisa qualitativa trata seu objeto de estudo como fruto do meio e analisa a totalidade do indivíduo no contexto onde ele se formou. Desse modo, os fatores externos são considerados e interferem nos resultados da pesquisa mostrando resultados contextualizados (GÜNTHER, 2006). A importância da referida pesquisa se justifica pelas características do conhecimento gerado por este meio, que é diferente do conhecimento produzido por meio de outras modalidades de pesquisa por ser mais concreto, mais contextualizado, mais voltado para a interpretação do leitor. Corroborando com os escritos citados, cabe salientar que a Situação de Estudo tem sido desenvolvida e analisada na região sul do país, num contexto cultural muito distinto dos apresentados na região nordeste, onde este estudo foi desenvolvido. Isso Ihe confere caraterísticas próprias e singulares, que podem ser uma contribuição importante para pesquisadores da referida forma de organização curricular.

A obtenção de dados para a pesquisa se deu por meio do desenvolvimento da Situação de Estudo que ocorreu numa turma de segundo ano do Ensino Médio, contendo 26 alunos, numa escola pública na cidade de Uruçuca localizada no sul da Bahia. A cidade tem características comuns a pequenos municípios do interior, com a população estimada em 2015, segundo o IBGE, de 21.849 habitantes. Embora a escola tenha características e influência rural, todos os alunos residem na zona urbana. Nessa escola, as aulas iniciam-se as 8:00 horas da manhã e acontecem nos dois turnos, tendo um intervalo de 20 minutos no meio de cada turno e uma hora para almoço. Os alunos que participaram da pesquisa apresentam idade variando entre 14 e 19 anos, com maior frequência de 14 e 15 anos de idade. Apenas um deles trabalha aos sábados, todos os outros não têm emprego e se dedicam quase que exclusivamente aos estudos.

Três professores da turma participaram do desenvolvimento, sendo que o próprio pesquisador é também professor de Química. Contou-se também com a participação dos professores de Física e Biologia. O professor de Física tem licenciatura na área e na época estava concluindo o mestrado em Ensino de Ciências e a professora de Biologia também é licenciada na área de atuação e tem mestrado em Zoologia. Ambos têm idade inferior aos 30 anos e cerca de cinco anos de experiência em docência no ensino médio.

A elaboração da Situação de Estudo teve um caráter muito particular, visto que era uma necessidade do projeto de pesquisa que foi apresentado numa das fases de seleção do Programa de Pós-Graduação em Educação em Ciências (PPGEC). Entretanto, antes do desenvolvimento das atividades, ocorreram diversas modificações oriundas de conversas e contribuições de professores e mestrandos das áreas de Química, Biologia e Física visando obter interações entre as áreas que é uma das características fundamentais da Situação de Estudo. Muito disso aconteceu durante as discussões nas aulas das disciplinas "Pesquisa em Educação em Ciências: tendências e metodologias" e "Formação de Professores no Ensino 
de Ciências", num momento em que o projeto de pesquisa sofria alterações para ganhar cunho metodológico e nessa ocasião interagi com colegas formados em diferentes áreas (Química, Física, Biologia, Pedagogia e Ciências da Natureza). Estas disciplinas proporcionaram diversos momentos de discussão acerca dos projetos de pesquisa dos alunos e nestes momentos, todos contribuíram com os projetos dos colegas expondo suas opiniões e dando sugestões.

Num segundo período, após definição de boa parte das etapas da pesquisa, as interações aconteceram com os professores da escola onde a pesquisa foi realizada, para que fossem planejadas todas as etapas do desenvolvimento da SE, visando ter a participação dos professores que atuariam no desenvolvimento das atividades propostas. Desse modo, foram planejadas algumas atividades e a forma como as aulas aconteceriam. Durante todo o processo, várias intervenções e ideias do orientador também foram consideradas na elaboração das etapas da SE.

A coleta de dados se deu por meio da observação de algumas aulas, com anotações e gravações de áudio. Por meio deste procedimento, foram obtidos dados referentes à dinâmica das aulas, registrando momentos importantes da interação professor-aluno. Não foram transcritas todas as falas dos envolvidos no processo, estas gravações serviram para fortalecer os dados obtidos por meio da observação. Foram escritas apenas falas julgadas representativas para a análise, com vista a minimizar os escritos e organizar de maneira mais simples os dados para compor o texto deste trabalho.

Gil (1987) alerta que a observação nada mais é que o uso dos sentidos de modo a adquirir informações essenciais à vida cotidiana, e, pode servir aos fins científicos, quando adota alguns critérios reguladores, tais como servir a um objetivo formulado de pesquisa, ser sistematicamente planejada, registrada e ligada a proposições mais gerais.

Além das observações, algumas etapas do desenvolvimento forneceram registros escritos, a exemplo dos textos produzidos ao final do método Jigsaw em dois momentos e também nas respostas às questões apresentadas nos roteiros dos experimentos.

Ao final do desenvolvimento da proposta, foi solicitado aos alunos que produzissem um vídeo, com duração aproximada de três minutos, abordando aspectos por eles julgados mais significativos da SE, nas três disciplinas. Os alunos ficaram livres para fazer o vídeo da maneira que achassem mais conveniente, entretanto, deveriam conversar com o professor de Química durante o processo, para que lhes fossem passadas orientações acerca das ideias propostas. Os vídeos produzidos foram exibidos no último dia de aula do bimestre, numa sala ampla, com projetor e som de boa qualidade, para duas turmas assistirem. Os vídeos serviram de instrumentos de análise e, para tanto, foram escritas diversas falas dos alunos nos vídeos, formando textos que configuram unidades de significado. Todos os textos foram analisados por meio de Análise Textual Discursiva (ATD), segundo Moraes e Galiazzi (2006), e serviram para ponderar as contribuições da referida Situação de Estudo para um ensino de Ciências interdisciplinar. 


\subsection{História: o início do desenvolvimento da SE}

A primeira aula da Situação de Estudo foi marcada pela apresentação da história do café, abordando as diversas lendas e fatos históricos que a compõe. Em princípio foi perguntado aos alunos como eles acreditavam ter surgido a primeira planta de café. Nesse momento todos puderam falar, e falaram em conjunto acrescentando fatos às falas dos colegas, pois todos acreditavam na evolução das espécies e falavam que o café deveria ter surgido de uma transformação ou hibridação de outra(s) planta(s). Após as falas dos alunos, lhes foi apresentada a versão mitológica de que a planta teria surgido por um milagre de Jesus.

Esse momento em que os estudantes participam ativamente da aula, expondo suas ideias e pensamentos, é defendido por Maldaner (2007) quando o autor ressalta a importância dos saberes, costumes e credos trazidos pelos estudantes em sua consciência. É necessário a criação de espaços para fala dos estudantes nas aulas, de modo a permitir a exposição desses saberes, para então o professor ser capaz de utilizá-los problematizando-os em sua aula.

Após a discussão dos estudantes acerca do surgimento da planta de café, o professor pesquisador tentou juntar as duas versões, fazendo surgir a ideia de que Jesus poderia ter feito o milagre num tempo mais longo, de modo a fazer uma planta qualquer sofrer transformação e evoluir até chegar à planta que temos hoje. Esclarecendo que seria apenas mais uma versão, e que cada um deveria juntar as informações para acreditar na versão que lhe parecesse mais coerente.

Isso concorda com os escritos de Maldaner (2007) quando o autor afirma que, no pensamento das pessoas, há lugar para o conhecimento científico e para os saberes mitológicos, não sendo necessário o abandono total de um, para aceitação completa do outro tipo de saber. Os dois podem e devem se complementar nas observações e explicações dos fatos cotidianos. Ainda nesse sentido, podemos concordar também com Santos e Schnetzler (2010), quando os autores escrevem que a função da escola é dar instrumentos para os estudantes desenvolverem o pensamento crítico, para se tornarem capazes de criar opinião própria frente a situações conflitantes.

Após a discussão acerca do surgimento da planta, a aula seguiu contando os fatos históricos que fizeram do café uma das bebidas mais consumidas no mundo inteiro. Mostrando os caminhos que passou até chegar ao Brasil. Em seguida foi exibido um pequeno vídeo, com título Café e Imigrantes, o vídeo tem duração de aproximadamente 07 minutos, aborda diversos fatos da História do Brasil que têm uma relação muito próxima com a produção de café.

Começa informando que um dos motivos que atrasaram o fim da escravidão no país, foi a necessidade de mão de obra para as lavouras de café, quando isso finalmente aconteceu, grande parte dos negros se recusaram a continuar trabalhando nas fazendas e seguiram para as cidades, geralmente, tornando-se mendigos. Por conta disso, muitos povos deixaram seus países e vieram trabalhar nas lavouras brasileiras para substituir os escravos negros, mudando as características étnicas do Brasil, influenciando a nossa cultura em diversos aspectos, dentre esses povos, os italianos merecem destaque devido ao número de pessoas.

Para abrigar as lavouras e os imigrantes, muitas aldeias indígenas foram destruídas violentamente para expulsar os povos que habitavam as áreas. Pouco 
tempo depois o Brasil já era responsável por quase $70 \%$ da produção mundial de café, a alta produção fez cair o preço do produto e, com isso, surgiu uma crise no país que só foi contornada pelo governo praticado na república do café com leite, que comprou e queimou a produção de café fazendo empréstimo no exterior e criando uma dívida externa que crescia continuamente.

Após a exibição do vídeo, os alunos comentaram sobre os fatos que acharam mais relevantes. Acho importante destacar a indignação de vários deles com a situação de manutenção da escravidão, para atender anseios de fazendeiros que queriam uma produção barata, de modo a vencer a concorrência no comércio internacional de café. Também foi destacado com repúdio, o desmatamento de florestas virgens para substituição por uma monocultura, diminuindo a diversidade da flora e fauna local. A aula foi finalizada pelo professor sugerindo uma comparação entre a situação discutida, e as condições agroflorestais da atualidade, incluindo as novas modalidades de trabalho escravo.

Este momento de discussão depois da exibição do vídeo é defendida por Rosa (2000) como uma necessidade, para uma melhor efetividade na compreensão da mensagem que o professor deseja transmitir aos seus alunos, e desta forma, despertá-los para algum momento que possa ter passado despercebido.

Assim, acredito que os alunos conseguiram perceber a relação entre o tema estudado e a História, notando como o consumo da bebida foi muito influente na sociedade ao longo do tempo, e continua influenciando o comércio mundial, com consequências em diversas áreas. $O$ procedimento relatado nesse item aconteceu em 04 aulas com duração de 50 minutos cada uma.

\subsection{Uma aula de Química e Física com dois professores}

A realização de uma aula interdisciplinar foi planejada com o professor de Física da escola que aceitou participar da proposta com algumas semanas de antecedência. Para isso, ele entendeu que poderíamos abordar conceitos relacionados à transferência de calor e trilhar caminhos para significar os conceitos de interações intermoleculares e temperatura de ebulição das substâncias. Isso já estava previsto no projeto de pesquisa e foi apenas apresentado ao professor dando-lhe espaço para aceitar, rejeitar ou sugerir as modificações que julgasse necessárias. Para detalhar atividades e organizar o modo como seriam realizadas as aulas, nós tivemos algumas poucas conversas informais e uma reunião onde os dois professores conseguiram planejar uma aula conjunta. O planejado foi colocado em prática na segunda parte da proposta, após as aulas de História, utilizando quatro aulas de 50 minutos cada, que eram normalmente destinadas à disciplina de Física no horário geral da escola.

No início da aula os alunos foram divididos em cinco grupos, quatro continham cinco estudantes e um tinha seis. Cada grupo recebeu uma lamparina acesa e um copo plástico descartável, o professor solicitou que eles submetessem o copo à chama da lamparina e observassem o tempo em que este sucumbiria. Em seguida cada grupo recebeu um copo igual ao anterior, entretanto este continha água. Questionou-se aos alunos o que eles acreditavam que aconteceria ao submeter o copo com água à chama. Alguns comentários ocorreram entre os alunos. Então, comparassem com o tempo que o copo vazio aguentou até derreter. A seguir, os 
alunos foram solicitados a propor explicações para a diferença de tempo entre as duas situações.

Dois alunos falaram que a água resfriava o copo, impedindo que ele derretesse, outro aluno completou afirmando: "a água absorve o calor da chama $e$, por isso, não esquenta o copo e ele não derrete tão rápido". Um dos grupos cronometrou os tempos, e registrou o valor de 3,66 segundos para derreter o fundo do copo vazio, enquanto que o copo com água demorou 2 minutos e 21 segundos, uma diferença de tempo significativa, proporcionando espaço para provocar explicações científicas dos alunos.

Os dois professores atuaram questionando cada uma das explicações propostas pelos estudantes, tentando organizar as ideias deles para construir um sentido, capaz de explicar o fenômeno observado. Em seguida, o professor de Física explicou, utilizando frases das falas dos alunos, como se dava a transferência de calor da chama para o copo, e do copo para a água que armazenava o calor, impedindo que este atuasse na destruição do copo.

Esse professor ressaltou a importância do termo "absorção de calor" como uma palavra representativa de um conceito físico e explicou como isso acontece. O uso de palavras representativas é defendido por Sangiogo et al. (2013) como uma necessidade para a compreensão do conteúdo estudado, os autores afirmam ser necessária a repetição destes termos para que ocorra apropriação do termo pelos alunos e, consequentemente, utilização destas palavras em seu vocabulário. Não basta apenas explicar o fenômeno e falar as palavras representativas do conceito uma única vez, é necessário repeti-las sempre que possível.

Em seguida, os alunos foram questionados acerca do comportamento da água enquanto absorvia calor, e chegou-se a uma questão problema sobre o comportamento da temperatura da água durante a ebulição. Notou-se que os alunos não conheciam significativamente o conceito de temperatura de ebulição. Eles foram convidados a executarem um experimento para aquecimento da água, observando o comportamento da temperatura com o passar do tempo. No momento da ebulição, os alunos foram questionados acerca do conteúdo das bolhas que se formavam no líquido, algumas respostas foram dadas, sempre seguidas de questionamentos dos professores tentando direcionar os pensamentos dos discentes para o objetivo da aula. Antes da conclusão, a aula foi interrompida devido ao término do horário, os estudantes foram convidados a buscarem respostas acerca do questionamento que ficou aberto nesta aula. Isso concorda com Francisco Jr, Ferreira e Hartwig (2008 p.36) quando os autores afirmam que "o papel do professor não é fornecer explicações prontas, mas problematizar com os alunos suas observações, ou seja, a leitura do experimento, fazendo-os reconhecer a necessidade de outros conhecimentos para interpretar os resultados experimentais". Isso corrobora com os preceitos da Situação de Estudo, no sentido de formar alunos reflexivos e críticos por meio de um processo de ensino em que ele seja participante ativo, não apenas um estudante passivo que apenas recebe informações (Pansera-de-Araújo, Auth e Maldaner 2007).

Na semana seguinte, foi feita uma breve revisão do ocorrido na aula anterior. Em seguida mostrou-se uma imagem expressando a forma como se dá a organização das moléculas de uma substância nos três diferentes estados de agregação da matéria. Logo após, foi explicado que as moléculas se mantém unidas por interações intermoleculares. Mostrou-se uma segunda imagem revelando 
como são organizadas as moléculas de água por meio de interações de hidrogênio. Explicou-se que, com o aumento de calor, aumenta também a energia cinética dessas partículas e, consequentemente, a sua agitação, até que seu movimento consiga romper as interações e mudando o estado de agregação fazendo com que a substância apresente-se num novo estado.

Foram explicadas as diferentes intensidades de cada tipo de interação, abordando também as características que fazem com que o mesmo tipo de força seja mais ou menos intensa em diferentes moléculas. Então questionou-se aos alunos: a quantidade de calor fornecida a água até a ebulição, será a mesma necessária para fazer o etanol ebulir? A partir das respostas chegou-se ao conceito de ponto de ebulição e o relacionou ao ponto de fusão. Foi discutido diversas vezes com a turma, as diferentes intensidades das interações intermoleculares e a singularidade entre elas, o que caracteriza as temperaturas de fusão e ebulição como uma especificidade de cada substância. Nesse contexto também se chegou a resposta sobre o conteúdo das bolhas (água em estado gasoso). Também concluímos que a temperatura da água em ebulição mantém-se constante devido ao escapamento de vapor de água para a atmosfera, levando consigo a energia que poderia causar aumento de temperatura. Então foi solicitado aos alunos a resolução das três questões sendo que uma delas solicitou a construção de um gráfico com os dados obtidos por meio do experimento de aquecimento da água, colocando a temperatura no eixo $\mathrm{Y}$ e o tempo no eixo $\mathrm{X}$, além de escrever observações relacionando o gráfico à temperatura de ebulição da água, bem como as interações de hidrogênio presentes na substância.

Os gráficos e as respostas foram entregues na semana seguinte, analisados por meio de observação das imagens e Análise Textual Discursiva. Observou-se que os alunos conseguiram perceber o que acontece com a temperatura da água durante a mudança de estado físico, do líquido para o gasoso. Ficou bastante claro também, que essa temperatura não é exatamente 100 ㄷ Como é apresentada em diversos livros, contribuindo para uma imagem de Ciência exata e precisa. Além disso, conseguiram compreender a relação existente entre as interações intermoleculares e a temperatura de ebulição da água, bem como relacionar este fato à formação de bolhas, que é uma característica da mudança de estado líquidogasoso. Pode-se acrescentar ainda, que perceberam com um bom nível de significação, o conceito de temperatura de ebulição como uma temperatura em que as moléculas da substância praticamente separam-se umas das outras gradativamente, formando bolhas de gás dessa mesma substância.

Assim, a interação entre as disciplinas Física e Química indicam uma positividade no sentido de melhoria no ensino do referido conteúdo, quando este é feito por meio de experimentação buscando respostas a uma questão prévia, que foi levantada e esclarecida com os estudantes, num ambiente de interação professor-aluno em que ambos são sujeitos construtores do processo. Isso concorda com os escritos de Francisco Jr, Ferreira e Hartwig (2008), ao defenderem a experimentação problematizadora e corrobora com as palavras de Maldaner (2007), que incentivam a utilização de interdisciplinaridade nas aulas de Ciências no Ensino Médio. 


\subsection{Preparando um café no laboratório de Química}

Nesse momento do desenvolvimento da Situação de Estudo, foi programada uma abordagem para o estudo das soluções. No início da aula os alunos participaram da degustação de três amostras de café, preparadas com quantidades bem distintas de pó de café e de açúcar. Essa degustação serviu como exemplo para os vários conceitos relacionados à solução e dispersão. Comparando o tamanho das partículas do pó de café e de açúcar, foi possível explicar a diferença entre dispersão coloidal e solução verdadeira e a probabilidade de decantação das partículas foi um exemplo visual que poderia diferenciar as classificações aqui mencionadas. Em seguida, abordamos os conceitos de soluto e solvente, para então seguir para as explicações acerca das quantidades destes dois componentes, o que caracteriza a concentração das soluções, muito bem expressas pelos estudantes como café forte ou fraco, relacionando-se o pó de café como soluto. Além disso, o café doce e amargo também foi um bom exemplo, ao adotar o açúcar como soluto. Para isso, foram utilizadas duas aulas de 50 minutos cada uma.

$\mathrm{Na}$ semana seguinte, foram formados 5 grupos, e solicitado que eles escrevessem uma receita explicando como deveriam proceder para preparar café no laboratório e os nomes de todos os materiais necessários para isso. Nesse processo, deveriam medir a massa de sacarose a ser utilizada. Após o preparo, o café deveria ser armazenado em balão volumétrico, tendo seu volume completado com água até a marca do menisco do balão. Dessa forma, seria preparada uma solução com quantidade conhecida de um dos solutos (sacarose). Essa parte da proposta foi realizada em duas aulas de 50 minutos cada uma.

Assim, os alunos foram convidados a produzir roteiros escritos por eles mesmos a partir de um processo muito comum no cotidiano de cada um: o preparo de café, sem apenas seguir normas e regras impostas pelo professor, o que caracteriza, em mais uma etapa desta proposta, o trabalho do aluno como ser capaz de produzir conhecimento, um dos atributos defendidos por Maldaner e Zanon (2006) como primordial no desenvolvimento das Situações de Estudo, e também por autores como Giordan (1999) e Laburú (2006) que rejeitam a experimentação onde os alunos apenas seguem um roteiro apresentado pelo professor, como meros executores de uma tarefa, desvinculada do seu contexto, sem impor no trabalho realizado, suas vontades, anseios nem curiosidades.

Após o preparo do café, os alunos foram solicitados a tentar resolver questões relacionadas à concentração de cafeína e sacarose no café produzido por eles, usando cálculos por meio de regra de três, usando unidades de massa por volume $(\mathrm{g} / \mathrm{L}$ e $\mathrm{mg} / \mathrm{mL})$. A tarefa pareceu fácil para eles, apenas alguns poucos apresentaram dificuldades. À medida que surgia alguma pergunta, Ihes eram feitos outros questionamentos, tentando direcionar o pensamento para raciocinar e resolver o problema, não foram dadas respostas prontas aos estudantes. Após isso, foi entregue uma lista com 20 questões com intuito de fixar o assunto estudado. $\mathrm{Na}$ semana seguinte foram introduzidas outras unidades de medida de concentração de soluções, como porcentagem, partes por milhão e molaridade, utilizando meios experimentais e lista de exercícios.

Além dessas etapas, o tema café também serviu para contextualizar os estudos acerca de processos de separação de misturas, utilizando o método Jigsaw. Os subtemas utilizados foram filtração, extração por solvente, decantação e evaporação, que foram passados aos alunos por meio de livros e vídeos em seus 
próprios celulares. Os estudantes realizaram de forma satisfatória as etapas de especialização e socialização do conhecimento, para finalizar, escreveram um texto reunindo as informações dos quatro membros, cada um especialista em um processo diferente, sintetizando explicações para os quatro processos de separação sobre os quais haviam estudado. Nesse processo, foi solicitado que exemplificassem com o preparo de café. Se passaram mais duas aulas de 50 minutos cada.

Por meio da observação, verificou-se grande aceitação dos alunos aos vídeos que o professor enviou aos seus smartphones, sem contudo abandonarem os livros que Ihes foram cedidos. Em momentos distintos, os quatro grupos de especialistas compararam o conteúdo do livro com as informações do vídeo que receberam. Isso mostra que os meios tecnológicos eletrônicos podem ser um importante fator colaborador para a melhoria do ensino, no sentido de aumentar a atenção dos estudantes e dessa forma, contribuir para um aprendizado mais significativo.

Assim percebemos a importância do professor estar atento às inovações e atualizações da sociedade. Ele precisa ter conhecimento dos desenvolvimentos científicos recentes para transmitir uma visão de ciência dinâmica, interagindo com diferentes campos do conhecimento, de forma a apresentar aos alunos uma visão de ciência interdisciplinar. Nesse aspecto, ele precisa saber selecionar conteúdos e métodos adequados que deem uma visão correta de ciência e que sejam interessantes aos alunos. Alunos estes que estão em contato constante com diversos meios de informação, e, portanto, têm conhecimento das mais recentes notícias acerca dos mais variados campos do conhecimento.

\subsection{O método Jigsaw para o estudo dos efeitos do café no corpo humano}

Esta parte da Situação de Estudo foi desenvolvida com apoio da professora de Biologia da escola. Para tal, nos reunimos e conversamos sobre o que estava previsto no projeto e observamos que coincidia com o planejamento do conteúdo que ela pretendia ministrar na turma escolhida para o desenvolvimento da pesquisa. Combinamos que o conteúdo abordado seriam alguns órgãos e sistemas do corpo humano, tendo como base, o consumo de café.

Duas aulas de Biologia foram observadas, com duração de 50 minutos cada uma; nessas aulas a professora iniciou questionando os alunos acerca da concentração de cafeína que contida numa xícara de café, pois isso já havia sido estudado nas aulas de Química. Em seguida perguntou aos alunos qual o caminho que a substância percorre no corpo humano, após a sua ingestão por meio da bebida. Os alunos deram algumas respostas e ela prosseguiu explicando que alguns órgãos são estudados em grupos, onde estes órgãos se combinam para desempenharem uma função semelhante, e são denominados sistemas, assim a boca, o esôfago, o estômago, o intestino, etc, são órgãos que compõem o sistema digestivo do corpo humano. Mostrou uma imagem com o desenho dos órgãos e simulou o caminho por onde o café passa ao ser consumido. Em seguida falou do sistema circulatório, responsável por levar a cafeína absorvida no estômago para os outros órgãos do corpo, até chegar ao cérebro, responsável por controlar todo o nosso sistema nervoso. Mostrou mais duas imagens representativas do sistema circulatório e sistema nervoso. 
Nesse momento, a professora explicou que o nosso cérebro controla todas as nossas atividades, citou vários exemplos de atividades, incluindo nossos momentos de descanso, normalmente programados para ocorrer enquanto estamos dormindo. Para nos fazer dormir, nosso corpo produz adenosina, esta substância libera neurotransmissores capazes de nos induzir ao sono, entretanto, como as estruturas químicas da adenosina e da cafeína são semelhantes, a cafeína consegue ocupar os receptores de adenosina em nosso cérebro, impedido a ação desta molécula, e, por conta disso, impede que nosso corpo sinta sensação de sono. Explicou isso enquanto mostrava imagens de desenhos de neurotransmissores e das estruturas das moléculas de adenosina e da cafeína.

A seguir, falou do sistema músculo esquelético e disse que a cafeína também causa efeitos nesses órgãos, mas que seriam discutidos na aula seguinte. Para completar a aula, solicitou que os alunos respondessem algumas questões previamente selecionadas no livro didático, referentes aos sistemas do corpo humano.

A aula seguinte foi planejada de maneira a integrar assuntos de Biologia com Química utilizando o método Jigsaw, para isso foram elaborados cinco textos com fragmentos de um artigo científico e uma revista dedicada ao público geral com informações relacionadas à saúde. Todos os textos tratavam dos efeitos do consumo de café nos seres humanos, relacionando-os à maior ou menor probabilidade de causar doenças, a exemplo do câncer em diversos órgãos. Primeiramente os professores explicaram a dinâmica da atividade a ser realizada, ressaltaram a importância de cada indivíduo no processo. Então cada grupo recebeu cinco textos distintos com informações relacionados aos efeitos do café no sistema nervoso central, sistema digestivo, cardiovascular, músculo esquelético e sistema respiratório. Foi solicitado que os textos fossem distribuídos entre os componentes do grupo, isso definiu os grupos de especialistas que foram formados em seguida com os estudantes que ficaram responsáveis por um mesmo texto.

O desenvolvimento dessa aula teve duração de aproximadamente 100 minutos, incluindo as quatro etapas do Jigsaw (formação dos grupos de base, especialização, socialização do conhecimento e escrita do texto). Na última etapa os alunos produziram textos em grupo, estes escritos foram analisados por ATD, por meio desta análise pode-se perceber que o Jigsaw é uma ferramenta de ensino capaz de promover a independência e o senso de protagonismo nos estudantes como construtores do próprio conhecimento através da busca de informações em meios de comunicação confiáveis, o que corrobora com os preceitos da Situação de Estudo no sentido da participação do aluno, trazendo seus conhecimentos da vida fora da escola e combinando-os com os saberes científicos apresentados no contexto escolar, como resultado disso, os saberes comuns tendem a evoluir para um sentido mais próximo do confiável e explicado pelos saberes escolares (MALDANER; ZANON, 2006).

Outra característica que merece destaque foi o senso de responsabilidade e cooperação dos estudantes, todos os envolvidos no desenvolvimento do Jigsaw cumpriram suas funções e foi perceptível a preocupação dos envolvidos na etapa de especialização, para obter conhecimento, como também na etapa de socialização do conhecimento, quando todos queriam falar sobre seus assuntos, até ultrapassarem o tempo estipulado para esta etapa. $O$ senso de cooperação é uma característica marcante do método Jigsaw conforme relatado por Leite et al. 
(2013), e foi observado tanto entre os componentes de um mesmo grupo de base, ao retornarem com o conhecimento a ser compartilhado, quanto nos grupos de especialistas quando discutiam o texto recebido.

Uma característica marcante do método Jigsaw é o número de componentes nos grupos, que deve ser o mesmo quantos forem os subtemas a serem trabalhados. Isso pode ser um problema quando a quantidade de alunos não permitir a formação dos grupos que o professor previamente planejou. Para esta etapa, estavam previstos a formação de cinco grupos, com cinco alunos em cada um, sendo que um grupo teria seis componentes e uma das tarefas seria realizada por uma dupla de alunos, ou seja, um texto seria compartilhado por dois alunos em um dos grupos, visto que haviam 26 alunos na turma. Entretanto, no dia de desenvolvimento desta etapa, dois alunos faltaram, o que impedia a realização do planejado. Nós explicamos a tarefa aos alunos e apresentamos o problema ocasionado pela ausência de dois estudantes, para resolver a situação, um deles propôs fazer duas vezes o seu papel na etapa de socialização do conhecimento, outros concordaram e também se dispuseram a cooperar da mesma maneira. Assim, um dos grupos foi formado com apenas quatro componentes e um aluno de outro grupo auxiliou na etapa final, trazendo informações acerca de um dos temas que não havia representante especialista neste grupo. $O$ que demonstra mais uma vez a característica de cooperação do referido método.

\subsection{Vídeos para sintetizar os estudos}

Ao final de um processo qualquer, é comum a necessidade de avaliação do que foi feito, buscando formas de averiguar o que houve de positivo e negativo no procedimento. Na educação isso também é comum e a avaliação aparece como uma ferramenta imprescindível para melhoria do ensino. Também é uma forma de fazer uma síntese do que foi estudado de modo a melhor fixá-lo e organizar as ideias que foram dispostas ao decorrer do estudo.

Nas Situações de Estudo a avaliação aparece como um fechamento e organização das etapas anteriores, de forma a demonstrar claramente o que foi estudado e as interações entre os conteúdos das diferentes disciplinas. Ao final do desenvolvimento de uma $\mathrm{SE}$, deve ser feito um fechamento com uma atividade que proporcione uma avaliação global do conhecimento que foi produzido, "isso engloba uma avaliação interdisciplinar e transdisciplinar sobre o uso de conceitos significados na análise de uma situação concreta que tenha relação com o estudo realizado" (MALDANER et al., 2007, p. 128). Dessa maneira, não está se rompendo apenas com a maneira tradicional de organizar o currículo, mas também com as formas de avaliação baseadas na memorização de conteúdos.

Considerando estes pressupostos, escolhemos por finalizar a SE com a exibição de vídeos produzidos pelos alunos. Eles foram orientados a produzir vídeos curtos, com duração de aproximadamente três minutos, sintetizando os conteúdos estudados da forma que achassem mais conveniente, entretanto, deveriam expor ao professor uma prévia do que pretendiam produzir nos vídeos. Dessa forma, estaríamos avaliando o que foi melhor assimilado pelos alunos de uma maneira não tradicional, numa produção independente da ação do professor, 
coube apenas a tarefa de vigiar os roteiros de modo impedir a exibição de algo muito fora das normas da escola, caso estivesse previsto nos roteiros.

Pela análise dos vídeos notou-se que os alunos conseguiram assimilar uma grande quantidade de conteúdos ministrados nas aulas por meio do desenvolvimento da Situação de Estudo, todos os vídeos abordaram assuntos de pelo menos três das quatro disciplinas ministradas, merece destaque à utilização de humor em todos os vídeos, como também as unidades de concentração de cafeína no café, relacionando o seu consumo à saúde humana, tanto trazendo possíveis benefícios quanto complicações. A relação do café no cotidiano das pessoas também foi abordada em todos os vídeos, atrelada aos efeitos estimulantes e/ou viciantes da bebida.

Desse modo observa-se que a produção de vídeos como instrumento de avaliação se mostrou uma respeitável ferramenta, visto que consegue abarcar diversas características desejáveis aos instrumentos avaliadores. Permite que os alunos expressem seus conhecimentos de uma maneira bastante independente, sem a tensão que normalmente marca os testes escritos, possibilita uma síntese do que foi estudado a partir do olhar dos estudantes, demonstrando o que eles acharam mais importante no processo e permitindo também uma avaliação da tarefa docente. Comporta a interdisciplinaridade e a contextualização de maneira muito significativa. Além de incorporar a tecnologia que nos cerca e ocupa espaço cada vez maior na vida das pessoas.

\section{CONSIDERAÇÕES FINAIS}

Esta pesquisa teve como objetivo geral, investigar a eficiência de uma Situação de Estudo como proposta curricular para alguns assuntos de Química, Física, Biologia e História de forma contextualizada e interdisciplinar, baseando-se no tema café, para isso foi organizada uma SE de modo a verificar a riqueza de contribuições possíveis para o tema em questão. Observou-se que o referido assunto apresenta uma grande possibilidade de abordagens a conteúdos de Ciências de modo a permitir a contextualização, a interdisciplinaridade e participação ativa dos alunos no processo, visto que trata-se de algo muito conhecido, que também é um dos requisitos para a escolha dos temas das Situações de Estudo.

O caráter social da bebida Ihe promoveu momentos Históricos significativos, tanto no Brasil como em outras partes do mundo, por conta disso, o tema contribui também para o ensino de História de maneira contextualizada e integrada às disciplinas Química, Física e Biologia. O cultivo da planta de café possibilita uma abordagem aos tipos de plantas, assunto presente nas aulas de Biologia que normalmente é ensinado de forma desconexa das outras disciplinas, mas que pode ser utilizado numa abordagem entre esta disciplina e Química, numa visão mais completa da composição química dos grãos de cada tipo de planta de café. 0 preparo da bebida permite uma significativa abordagem a diversos tipos de separação de misturas, além de conceitos relacionados à transferência de calor e equilíbrio térmico, mostrando mais uma vez o caráter interdisciplinar da proposta. Além disso, o consumo da bebida provoca diversos efeitos no organismo humano, dentre eles, merece destaque a sensação de alerta e a probabilidade de dependência à cafeína, bem como o aumento na tendência em desenvolver alguns 
tipos de doenças e até mesmo a prevenção a outros tipos. O que se configura numa abordagem relacionada a aspectos sociais relacionando ideias que os estudantes já conhecem do saber comum e atrelando-as aos saberes escolares científicos. Desse modo, notou-se que o tema café apresenta as características desejáveis para o desenvolvimento de uma Situação de Estudo, capaz de contribuir com o ensino de Ciências de forma contextualizada e interdisciplinar.

No que se refere ao uso das estratégias de ensino adotadas no desenvolvimento da Situação de Estudo desse trabalho, foi observada uma grande aceitação dos estudantes às três modalidades empregadas. A experimentação com caráter problematizador promoveu uma intensa participação oral dos alunos, o que auxilia o processo, por conferir importância aos sujeitos como participantes ativos. Além de contribuir muito significativamente com a aprendizagem e assimilação dos conceitos de Química e de Física que foram abordados por este meio.

Algo similar aconteceu com a utilização do vídeo nas aulas relacionadas à História, no momento de debate de ideias, vários estudantes comentaram sobre pontos sociais, rejeitando ações consideradas por eles como injustiças relacionadas ao cultivo de café. $O$ que caracteriza o forte poder de influência na formação para a cidadania promovido pela escolarização de modo voltado a esse aspecto.

O desenvolvimento do método Jigsaw em dois momentos da proposta conferiu grande caráter de independência aos estudantes, aliado a isso, notou-se grande senso de companheirismo e responsabilidade entre os alunos envolvidos, pois todos reconheceram a importância de sua participação no processo, não apenas para seu próprio aprendizado, mas também como responsáveis por levar conhecimento aos colegas do grupo de base. A utilização de vídeos nos smartphones foi uma etapa muito bem aceita e desempenhou papel fundamental na assimilação dos conteúdos inclusos nesta etapa. Vale ressaltar, entretanto, a rejeição dos estudantes em escrever o texto reunindo informações de todos os diferentes especialistas que compunham o grupo final, mostrando uma certa dificuldade na escrita manual, algo que já parece característico dessa geração altamente tecnológica. O que nos leva a pensar em formas alternativas para resolver o problema, talvez proporcionando outros momentos em que os alunos sejam convidados a escrever, por exemplo, propondo formas alternativas que aliem o hábito de escrever a atividades lúdicas.

Pode-se perceber que o uso de experimentação com caráter problematizador, exibição de vídeo seguido de discussão e Jigsaw, são estratégias de ensino compatíveis com o desenvolvimento de Situações de Estudo, por apresentarem características muito próximas das desejáveis por esta forma de organização curricular, com destaque para a participação do aluno como sujeito interativo e formação de cidadãos capazes de tomar decisões e interferir no meio em que vivem de maneira consciente.

A utilização da produção de vídeos como instrumento de avaliação do desenvolvimento da proposta mostrou-se uma estratégia viável e compatível com os preceitos da Situação de Estudo, uma vez que os estudantes ficaram livres para elaborar um pensamento lógico sobre o tema, envolvendo diversos conteúdos estudados através de estratégias diferentes e meios de informação distintos. Esse pensamento foi executado numa sequência cronológica definida por eles próprios 
e, ao professor, coube a tarefa de analisar previamente o que eles pretendiam expor, evitando deste modo, constrangimentos e situações desnecessárias. Aliado a esse modo de avaliação, está o uso das tecnologias, algo muito utilizado por praticamente todos os adolescentes das escolas urbanas atuais, que, desta forma, aparece como aliado ao professor numa tarefa muito complicada, que é avaliar o processo de ensino de uma forma que os estudantes gostem e concordem em fazer.

Assim, pode-se afirmar que o desenvolvimento de uma Situação de Estudo com o tema café, utilizando experimentação, Jigsaw e vídeos nas aulas de Ciências do Ensino Médio, favorece o ensino contextualizado de diversos conteúdos numa maneira interdisciplinar, além de favorecer a formação de estudantes ativos e participantes do processo educacional. 


\title{
The our coffee every day: research the influence of a study situation in the process of nature sciences learning teaching in secondary education
}

\begin{abstract}
Coffee is one of the most consumed beverages in the world, this factor can be powerful tool for teaching in context of Sciences, since traditional education has not achieved great results with today's students promoting the lack of attention and discouraging students who, in most cases, fail to realize the relationship between the contents studied in the classroom and their social life. Therefore, the study situation (SE) appears as an important promise of evolution in the curriculum reform camp, where the contents are worked collectively and seamlessly. In this text I present reports of a master's research, whose objective was to investigate the efficiency of a study situation as proposed curriculum for some subjects Chemistry, Physics, Biology and History in context and interdisciplinary way, based on coffee theme.
\end{abstract}

KEYWORDS: Science study. Situation study. Coffee. 


\section{REFERÊNCIAS}

BOFF, E.; PANSERA-DE-ARAÚJO, M. A Significação do Conceito Energia no Contexto da Situação de Estudo Alimentos: Produção e Consumo. Revista Brasileira de Pesquisa em Educação em Ciências, v. 11, n. 1, p. 123-142, 2011.

BRASIL. Ministério da Educação. Secretaria de Educação Média e Tecnológica. Parâmetros Curriculares Nacionais, 1999.

CHASSOT, A. I. Para Que(m) É Útil o Ensino? Canoas: ULBRA, 1995.

FATARELI, E. F. et al. Método cooperativo de aprendizagem Jigsaw no ensino de cinética química. Química Nova na Escola, v. 32, n. 3, p. 161-168, 2010.

FRANCISCO JR, W. E.; FERREIRA, L. H.; HARTWIG, D. R. Experimentação Problematizadora: Fundamentos Teóricos e Práticos para a Aplicação em Salas de Aula de Ciências. Química Nova na Escola, n. 30, p. 34-41, 2008.

FREIRE, P. Pedagogia do Oprimido. 17. ed. Rio de Janeiro: Paz e Terra, 1987.

FRISON, M. D. et al. Conhecendo o Câncer, Um Caminho para a Vida: uma Situação de Estudo como possibilidade de mudança no fazer cotidiano escolar. In: GALIAZZI, M. C. et al. (Eds.). . Construção Curricular em Rede na Educação em Ciências: uma aposta de pesquisa em sala de aula. Ijuí: Editora Unijuí, 2007. p. 337-355.

GALETI, P. A. Pelos caminhos do café. Campinas: CATI, 2004.

GIL, A. C. Métodos E Técnicas De Pesquisa Social. 1. ed. São Paulo: Atlas, 1987.

GIORDAN, M. O papel da experimentação no ensino de Ciências. Química Nova na Escola, n. 10, p. 43-49, 1999.

GÜNTHER, H. Pesquisa qualitativa versus pesquisa quantitativa: esta é a questão? Psicologia: Teoria e Pesquisa, v. 22, n. 2, p. 201-209, 2006. ao ensino de nanociência e nanotecnologia. Revista Brasileira de Ensino de 
Física, v. 35, n. 4, p. 4504-1-4504-7, 2013.

LUDKE, M.; ANDRÉ, M. E. D. A. Pesquisa em educação: abordagens qualitativas. E.P.U. ed. São Paulo: [s.n.].

MALDANER, O. A. Produção Coletiva e Inovação Curricular como Mediação da Formação Continuada de Professores. V ANPEDSUL. Anais...2004

MALDANER, O. A. Situações de Estudo no Ensino Médio: nova compreensão de educação básica. In: NARDI, R. (Ed.). . A Pesquisa em Ensino de Ciênicas no Brasil: Alguns Recortes. São Paulo: Escrituras Editora, 2007. p. 239-253.

MALDANER, O. A. et al. Currículo Contextualizado na Área de Ciências da Natureza e Suas Tecnologias: a Situação de Estudo. In: MALDANER, O. A.; ZANON, L. B. (Eds.). . Fundamentos e Propostas do Ensino de Química para a Educação Básica no Brasil. ljuí: Editora Unijuí, 2007. p. 224.

MALDANER, O. A.; ZANON, L. B. Situação de Estudo: uma Organização do Ensino que Extrapola a Formação Disciplinar em Ciências. In: MORAES, R.; MANCUSO, R. (Eds.). . Educação em Ciências: produção de currículos e formação de professores. 2. ed. ljuí: Editora Unijuí, 2006.

MORAES, R.; GALIAZZI, M. D. C. Análise textual discursiva: processo reconstrutivo de múltiplas faces. Ciência \& Educação, v. 12, n. 1, p. 117-128, 2006.

MORAES, R.; MANCUSO, R. Educação em Ciências: Produção de currículos e formação de professores. ljuí: [s.n.].

MORIN, E. Os sete saberes necessários à educação do futuro. 2 .ed ed. São Paulo: Cortez, 2000.

PANSERA-DE-ARAÚJO, M. C.; AUTH, M. A.; MALDANER, O. A. Situações de Estudo como Forma de Inovação Curricular em Ciências Naturais. In: GALIAZZI, M. DO C. et al. (Eds.). . Construção Curricular em Rede na Educação em Ciências: uma aposta de pesquisa em sala de aula. ljuí: Editora Unijuí, 2007. p. 161-176.

ROSA, P. R. S. O Uso Dos Recursos Audiovisuais E O Ensino De Ciências. Caderno Catarinense de Ensino de Física, v. 17, n. 1, p. 33-49, 2000.

SANGIOGO, F. A. et al. Pressupostos Epistemológicos que Balizam a Situação de 
SANTOS, W.; SCHNETZLER, R. Função social: o que significa ensino de química para formar o cidadão. Química Nova na Escola, n. 4, p. 28-34, 1996.

SANTOS, W.; SCHNETZLER, R. Educação em Química: compromisso com a cidadania. 4. ed. ljuí: Editora Unijuí, 2010.

SILVA, J. M. P. et al. ÁGUA, FATOR DETERMINANTE PARA A VIDA: uma possibilidade de articulação da Biologia e Química no Ensino Médio. In: GALIAZZI, M. C. et al. (Eds.). . Construção Curricular em Rede na Educação em Ciências: uma aposta de pesquisa em sala de aula. ljuí: Editora Unijuí, 2007. p. 408.

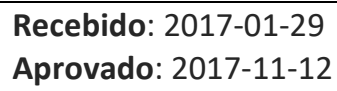
influência de uma situação de estudo no processo de ensino aprendizagem de ciências da natureza no ensino médio. Revista Brasileira de Ensino de Ciência e Tecnologia, v. 11, n. 1, 2018. Disponível em:

<https://periodicos.utfpr.edu.br/rbect/article/view/5370>. Acesso em: xxx.

Correspondência: Danilo de Jesus - danilo.quimica@hotmail.com

Direito autoral: Este artigo está licenciado sob os termos da Licença Creative Commons-Atribuição 4.0 Internacional.

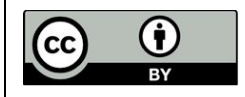

